\title{
The Effect of Discharging Patients with Low Hemoglobin Levels on Hospital Readmission and Quality of Life after Adult Spinal Deformity Surgery
}

\author{
Vugar Nabi ${ }^{1}$, Selim Ayhan ${ }^{2}$, Selcen Yuksel ${ }^{3}$, Prashant Adhikari ${ }^{4}$, Alba Vila-Casademunt ${ }^{5}$, \\ Ferran Pellise ${ }^{5}$, Francisco Sanchez Perez-Grueso ${ }^{6}$, Ahmet Alanay ${ }^{7}$, Ibrahim Obeid $^{8}$, \\ Frank Kleinstueck ${ }^{9}$, Emre Acaroglu $^{10}$, European Spine Study Group ${ }^{5}$ \\ ${ }^{1}$ Department of Orthopaedics and Traumatology, Antalya Research and Education Hospital, Ministry of Health, University of Health Science, Antalya, Turkey \\ ${ }^{2}$ Department of Neurosurgery, Baskent University Hospital, Ankara, Turkey \\ ${ }^{3}$ Department of Biostatistics, Yildirim Beyazit University, Ankara, Turkey \\ ${ }^{4}$ ARTES Spine Center, Acibadem Ankara Hospital, Ankara, Turkey \\ ${ }^{5}$ Hospital Universitari Valld'Hebron, Barcelona, Spain \\ ${ }^{6}$ Hospital Universitari La Paz, Madrid, Spain \\ ${ }^{7}$ Department of Orthopaedics and Traumatology, Acibadem Mehmet Ali Aydinlar University School of Medicine, Istanbul, Turkey \\ ${ }^{8}$ Bordeaux University Hospital, Bordeaux, France \\ ${ }^{9}$ Schultess Clinic, Zurich, Switzerland \\ ${ }^{10}$ Ankara Spine Center, Ankara, Turkey
}

Study Design: Retrospective cohort.

Purpose: This study aims to evaluate the impact of anemia on functional outcomes, health-related quality of life (HROOL), and early hospital readmission (EHR) rates after adult spinal deformity (ASD) surgery at the time of discharge from the hospital.

Overview of Literature: Concerns with risks of transfusion, insufficient evidence for its benefits, and the possibility of associated adverse outcomes have led to restrictive transfusion practices. Therefore, patients are discharged according to patient blood management programs that are implemented in hospitals nationwide to reduce unnecessary blood transfusions. However, not many comprehensive kinds of studies exist on the effect of postoperative anemia on functional life and complications.

Methods: Anemia severity was defined following the 2011 World Health Organization guidelines. All patients had HROoL tests as well as complete blood counts pre- and postoperatively. EHR is the admission within 30 days of discharge and was used as the dependent parameter.

Results: This study comprised 225 surgically treated ASD patients with a median age of 62.0 years, predominantly women (80\%). Of the 225 patients, 82,137 , and six had mild, moderate, and severe anemia at the time of discharge, respectively. Seventeen of the patients (mild [11,64.7\%]; moderate [5, 29.4\%]; severe [1, 5.9\%]) were readmitted within 30 days. The mean hemoglobin values were higher in readmitted patients $(p=0.071)$. Infection was the leading cause of readmission $(n=12)$, but a low hemoglobin level was not observed in any of these patients at the time of discharge. Except for Scoliosis Research Society-22 questionnaire, HROoL improvements did not reach statistical significance in early readmitted patients in the first year after surgery.

Received Dec 9, 2020; Revised Apr 27, 2021; Accepted Apr 29, 2021

Corresponding author: Emre Acaroglu

Ankara Spine Center, Iran Caddesi, 45/2, Kavaklidere, 06700, Cankaya, Ankara, Turkey

Tel: +90-312-467-0442, Fax: +90-312-467-3915, E-mail: acaroglue@gmail.com 
Conclusions: The results of this study demonstrated that the occurrence and the severity of postoperative anemia are not associated with EHR in surgically treated patients with ASD. The findings of the current research suggested that clinical awareness of the parameters other than postoperative anemia may be crucial. Thus, improvements in HROoL scores were poor in early readmitted patients 1 year after surgery.

Keywords: Adult spine deformity; Anemia; Health-related quality of life; Hospital readmission; Patient outcome assessment

\section{Introduction}

The circulatory and hematopoietic systems have evolved to bridge the gap between the outside world, where resources are plentiful, and the immediate vicinity of the cells. Any condition compromising this long and tightly regulated chain of supply can result in significant harm. Anemia, the oxygen-carrying capacity of the blood, and its rheological characteristics are compromised in one such condition [1,2].

Nature does not necessarily comply with the human desire to often categorize using arbitrary criteria. Anemia is a good example because the search for the physiologic hemoglobin $(\mathrm{Hb})$ threshold to define anemia remains unfulfilled [3].

Anemia has been associated with increased mortality, higher incidence of cardiovascular disease, cognitive impairment, and increased risk of falls and fractures $[4,5]$. Major surgeries, e.g., adult spinal deformity (ASD) surgery, are associated with significant blood loss, and often result in postoperative anemia [6]. Concerns with risks of transfusion, insufficient evidence for its benefits, and the possibility of associated adverse outcomes have led to restrictive transfusion practices. Therefore, patients are discharged according to patient blood management programs that are implemented in hospitals nationwide to reduce unnecessary blood transfusions [2,7]. Moreover, patients undergoing spinal deformity surgery are asked to ambulate as soon as possible. This circumstance increases metabolic demand. Moreover, anemia could also affect functional recovery after major orthopedic surgery by decreasing postoperative vigor and quality of life (QoL) [8,9].

Evident literature is insufficient to demonstrate whether low $\mathrm{Hb}$ values at discharge may affect readmission rates and functional outcomes after ASD surgery. Thus, this study aims to identify the impact of anemia on QoL and early hospital readmission (EHR) rates from any cause after ASD surgery.

\section{Materials and Methods}

This retrospective study was conducted on a prospectively collected multicenter ASD database. The criteria for database inclusion were defined as having any or any combination of thoracic kyphosis exceeding $60^{\circ}$, coronal deformity exceeding $20^{\circ}$, pelvic tilt exceeding $25^{\circ}$, and sagittal vertical axis exceeding $50 \mathrm{~mm}$. All patients were enrolled into an institutional review board-approved protocol in the respective sites. This study was approved by the Clinical Research Ethics Committee of Vall d'Hebron University (approval no., 181-10/2010). Moreover, the patients consented to be enrolled in the database as well as in the present study. Baseline demographic data (age, gender, comorbidities, and body mass index), health-related QoL (HRQoL) parameters (The Core Outcome Measures Index, The Oswestry Disability Index [ODI], 36-item Short-Form Health Survey [SF-36] mental component summary, SF-36 physical component summary [PCS], and Scoliosis Research Society-22 questionnaire [SRS22]), and radiological features (sagittal vertical axis, T2T12 kyphosis, coronal balance, major curve Cobb angle, lordosis gap [10], global tilt [11], and T1 sagittal tilt [12]) were included. Patients were also stratified according to the etiology of their deformity (i.e., idiopathic, degenerative, and others). Demographical, clinical, and radiological characteristics and HRQoL parameters at baseline and 1 year postsurgery were extracted. Reports of research followed the principles of the Declaration of Helsinki.

\section{Hemoglobin evaluation}

Anemia severity was defined following the 2011 World Health Organization (WHO) guidelines [3]. The WHO defined three levels according to $\mathrm{Hb}$ concentrations, i.e., 
Table 1. Descriptive analysis of the study population and early readmitted patients

\begin{tabular}{|c|c|}
\hline Characteristic & Value \\
\hline \multicolumn{2}{|l|}{ Characteristic of the study population } \\
\hline \multicolumn{2}{|l|}{ Gender } \\
\hline Female & $180(80.0)$ \\
\hline Male & $44(19.6)$ \\
\hline \multicolumn{2}{|l|}{ Early readmission } \\
\hline Yes & $17(7.6)$ \\
\hline No & $208(92.4)$ \\
\hline \multicolumn{2}{|l|}{ Diagnosis } \\
\hline Degenerative & $83(36.9)$ \\
\hline Idiopathic & $103(45.8)$ \\
\hline Other & $38(16.9)$ \\
\hline Age (yr) & $62.0(18-85)$ \\
\hline $\mathrm{BMI}\left(\mathrm{kg} / \mathrm{m}^{2}\right)$ & $24.0(16-39)$ \\
\hline Total surgical time (min) & $210(50-768)$ \\
\hline SICU length of stay (hr) & $24(0-168)$ \\
\hline Hemoglobin at discharge (g/dL) & $10.50(7.40-14.90)$ \\
\hline Length of hospitalization (day) & $9.0(2-83)$ \\
\hline Blood loss (mL) & $1,000(40-6,500)$ \\
\hline Total transfused blood (mL) & $550(0-5,135)$ \\
\hline No. of posterior instrumented levels & $9(2-19)$ \\
\hline No. of prior spine surgery & 48 \\
\hline No. of first surgical approach (anterior vs. posterior) & $3 / 209$ \\
\hline No. of ASA classification 1/2/3 & $60 / 116 / 36$ \\
\hline No. of antifibrinolytics & 57 \\
\hline No. of graft & 206 \\
\hline No. of osteotomy & 96 \\
\hline \multicolumn{2}{|l|}{ Characteristic of early readmitted patients } \\
\hline \multicolumn{2}{|l|}{ Gender } \\
\hline Female & $14(82.4)$ \\
\hline Male & $3(17.6)$ \\
\hline \multicolumn{2}{|l|}{ Diagnosis } \\
\hline Degenerative & $7(41.2)$ \\
\hline Idiopathic & $7(41.2)$ \\
\hline Other ${ }^{a)}$ & $3(17.6)$ \\
\hline Age (yr) & $61.24 \pm 16.34$ \\
\hline $\mathrm{BMI}\left(\mathrm{kg} / \mathrm{m}^{2}\right)$ & $24.94 \pm 4.17$ \\
\hline Total surgical time (min) & $210(62-496)$ \\
\hline SICU length of stay (hr) & $24(0-72)$ \\
\hline Hemoglobin at discharge $(\mathrm{g} / \mathrm{dL})$ & $11.26 \pm 1.67$ \\
\hline Length of hospitalization (day) & $8(2-42)$ \\
\hline Blood loss (mL) & $700(50-1,800)$ \\
\hline
\end{tabular}

Table 1. Continued

\begin{tabular}{lc} 
Characteristic & \multicolumn{1}{c}{ Value } \\
\hline Total transfused blood (mL) & $400(0-1,440)$ \\
\hline $\begin{array}{l}\text { No. of posterior instrumented levels } \\
\text { No. of prior spine surgery }\end{array}$ & $9(2-18)$ \\
\hline $\begin{array}{l}\text { No. of first surgical approach (anterior vs. posterior } \\
\text { approach) }\end{array}$ & $0 / 17$ \\
\hline $\begin{array}{l}\text { No. of ASA classification 1/2/3 } \\
\text { No. of antifibrinolytics }\end{array}$ & $3 / 8 / 6$ \\
\hline No. of graft & 6 \\
\hline No. of osteotomy & 16 \\
\hline
\end{tabular}

Values are presented as number (\%), median (min-max), number, or mean \pm standard deviation, unless otherwise stated.

$\mathrm{BMI}$, body mass index; SICU, surgical intensive care unit; ASA, American Society of Anesthesiologists.

alFailed-back, post-traumatic, Scheuermann, neuromuscular, congenital, postinfection.

mild (11-11.9 g/dL in adult females; $11-12.9 \mathrm{~g} / \mathrm{dL}$ in adult males), moderate (8-10.9 $\mathrm{g} / \mathrm{dL}$ in adult females or males), and severe $(<8 \mathrm{~g} / \mathrm{dL}$ in either gender). Patients who had complete blood counts at the latest time during hospitalization for surgery or at the time of discharge were assessed.

\section{Readmission}

EHR, defined as the readmission within 30 days of discharge, was used as the dependent parameter because the more time that passes between readmission and discharge, the less likely it is to be associated with a negative condition at discharge [13].

\section{Statistical analysis}

Nonparametric test statistics were used to evaluate the relationship between variables. Spearman's rho correlation coefficient was used to test the correlation between continuous variables. The Mann-Whitney $U$-test and the Kruskal-Wallis test were used to compare two and more than two groups, respectively, according to $\mathrm{Hb}$ values. Linear regression was used to predict $\mathrm{Hb}$ level for gender categories. Furthermore, dummy coding was used to take gender as an independent variable. The type-I error rate was taken as $\alpha=0.05$ for statistical significance. IBM SPSS for Windows ver. 21.0 (released 2012; IBM Corp., Armonk, NY, USA) was used for analyses. 
Table 2. Comorbidities of early hospital readmitted patients

\begin{tabular}{|c|c|c|c|c|}
\hline \multirow{3}{*}{ Comorbidities } & \multicolumn{4}{|c|}{ Early hospital readmission } \\
\hline & \multicolumn{2}{|c|}{ No } & \multicolumn{2}{|c|}{ Yes } \\
\hline & Absent & Present & Absent & Present \\
\hline None & 155 (79.49) & $40(20.51)$ & $13(76.47)$ & $4(23.53)$ \\
\hline AIDS & $195(100.00)$ & 0 & $17(100.00)$ & 0 \\
\hline Alcohol/drug abuse & $191(97.95)$ & $4(2.05)$ & $17(100.00)$ & 0 \\
\hline Allergy & 189 (96.92) & $6(3.08)$ & $16(94.12)$ & $1(5.88)$ \\
\hline Anemia or other blood disorders & $176(90.26)$ & $19(9.74)$ & $17(100.00)$ & 0 \\
\hline Any non-metastatic solid tumor & $176(90.26)$ & 19 (9.74) & $14(82.35)$ & $3(17.65)$ \\
\hline Cardiac & 179 (91.79) & $16(8.21)$ & $15(88.24)$ & $2(11.76)$ \\
\hline Cerebrovascular disease & $193(98.97)$ & $2(1.03)$ & $15(88.24)$ & $2(11.76)$ \\
\hline Chronic pulmonary disease & 175 (89.74) & $20(10.26)$ & $16(94.12)$ & $1(5.88)$ \\
\hline Connective tissue disease, autoimmune & 186 (95.38) & $9(4.62)$ & $17(100.00)$ & 0 \\
\hline Depression, anxiety & $153(78.46)$ & $42(21.54)$ & $12(70.59)$ & $5(29.41)$ \\
\hline Diabetes with end organ damage & $195(100.00)$ & 0 & $17(100.00)$ & 0 \\
\hline Diabetes without complications & 186 (95.38) & $9(4.62)$ & $17(100.00)$ & 0 \\
\hline Dyslipidemia & 182 (93.33) & $13(6.67)$ & $16(94.12)$ & $1(5.88)$ \\
\hline EENT (eye, ear, nose, throat, larynx) & 189 (96.92) & $6(3.08)$ & $17(100.00)$ & 0 \\
\hline Endocrine & 179 (91.79) & $16(8.21)$ & $13(76.47)$ & $4(23.53)$ \\
\hline Fibromyalgia & $194(99.49)$ & $1(0.51)$ & $17(100.00)$ & 0 \\
\hline Hemiplegia & $195(100.00)$ & 0 & $17(100.00)$ & 0 \\
\hline Hypertension & $137(70.26)$ & $58(29.74)$ & $10(58.82)$ & $7(41.18)$ \\
\hline Upper Gl & $178(91.28)$ & $17(8.72)$ & $17(100.00)$ & 0 \\
\hline Lower Gl & $191(97.95)$ & $4(2.05)$ & $17(100.00)$ & 0 \\
\hline Peptic ulcer & $195(100.00)$ & 0 & $17(100.00)$ & 0 \\
\hline Lymphatic system disorder & $195(100.00)$ & 0 & $17(100.00)$ & 0 \\
\hline Metabolic disorders & 192 (98.46) & $3(1.54)$ & $17(100.00)$ & 0 \\
\hline Metastatic solid tumor & $195(100.00)$ & 0 & $17(100.00)$ & 0 \\
\hline Mild liver disease & $186(95.38)$ & $9(4.62)$ & $17(100.00)$ & 0 \\
\hline Moderate or severe liver disease & $195(100.00)$ & 0 & $17(100.00)$ & 0 \\
\hline Musculo-skeletal-integumentary & $185(94.87)$ & $10(5.13)$ & $15(88.24)$ & $2(11.76)$ \\
\hline Nervous system disorders & $187(95.90)$ & $8(4.10)$ & $15(88.24)$ & $2(11.76)$ \\
\hline Osteoarthritis & $131(67.18)$ & $64(32.82)$ & $12(70.59)$ & $5(29.41)$ \\
\hline Osteoporosis/osteopenia & $160(82.05)$ & $35(17.95)$ & $15(88.24)$ & $2(11.76)$ \\
\hline Other GU & 191 (97.95) & $4(2.05)$ & $17(100.00)$ & 0 \\
\hline Infectious diseases & 193 (98.97) & $2(1.03)$ & $17(100.00)$ & 0 \\
\hline Other previous surgeries & 179 (91.79) & $16(8.21)$ & $16(94.12)$ & $1(5.88)$ \\
\hline Peripheral vascular disease & 193 (98.97) & $2(1.03)$ & $16(94.12)$ & $1(5.88)$ \\
\hline Mild vascular & 182 (93.33) & $13(6.67)$ & $16(94.12)$ & $1(5.88)$ \\
\hline Pregnancy & $195(100.00)$ & 0 & $17(100.00)$ & 0 \\
\hline Psychiatric/behavioral & 187 (95.90) & $8(4.10)$ & $16(94.12)$ & $1(5.88)$ \\
\hline Dementia & $195(100.00)$ & 0 & $17(100.00)$ & 0 \\
\hline Renal & 185 (94.87) & $10(5.13)$ & $16(94.12)$ & $1(5.88)$ \\
\hline Malignant lymphoma & $195(100.00)$ & 0 & $17(100.00)$ & 0 \\
\hline Leukemia & $195(100.00)$ & 0 & $17(100.00)$ & 0 \\
\hline
\end{tabular}

Values are presented as number (\%).

AIDS, acquired immunodeficiency syndrome; GI, gastrointestinal. GU, genitourinary. 
Table 3. Radiological parameters of the patients

\begin{tabular}{|c|c|c|c|}
\hline Variable & $\begin{array}{c}\text { Early } \\
\text { readmission }\end{array}$ & $\begin{array}{c}\text { No. of } \\
\text { patients }^{\text {a) }}\end{array}$ & $\begin{array}{l}\text { Median } \\
\text { (min to max) }\end{array}$ \\
\hline \multirow[t]{2}{*}{ Major curve Cobb angle $\left({ }^{\circ}\right)$} & Yes & 11 & 20 (4 to 38) \\
\hline & No & 167 & 18 (2 to 66$)$ \\
\hline \multirow[t]{2}{*}{ Lordosis (top of L1-S1) $\left(^{\circ}\right)$} & Yes & 11 & 49 (10 to 77$)$ \\
\hline & No & 181 & 52 (25 to 88 ) \\
\hline \multirow[t]{2}{*}{ Global tilt $\left({ }^{\circ}\right)$} & Yes & 11 & 30 (1 to 58$)$ \\
\hline & No & 177 & $21(-11$ to 61$)$ \\
\hline \multirow[t]{2}{*}{ T1 sagittal tilt $\left({ }^{\circ}\right)$} & Yes & 11 & $7(1$ to 15$)$ \\
\hline & No & 160 & 5 (1 to 17$)$ \\
\hline \multirow[t]{2}{*}{ T2-T12 kyphosis $\left({ }^{\circ}\right)$} & Yes & 11 & 43 (16 to 68$)$ \\
\hline & No & 176 & 46 (2 to 93) \\
\hline \multirow[t]{2}{*}{ Pelvic tilt $\left({ }^{\circ}\right)$} & Yes & 11 & 29 (6 to 38$)$ \\
\hline & No & 181 & 20 (-3 to 46$)$ \\
\hline \multirow[t]{2}{*}{ Pelvic incidence $\left({ }^{\circ}\right)$} & Yes & 11 & 62 (42 to 84) \\
\hline & No & 181 & 55 (24 to 92) \\
\hline \multirow[t]{2}{*}{ Sagittal balance $(\mathrm{mm})$} & Yes & 11 & 30.6 (-36 to 139$)$ \\
\hline & No & 166 & 15.1 (-76 to 152$)$ \\
\hline
\end{tabular}

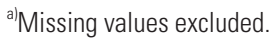

Table 4. Median hemoglobin values of the patients at discharge and comparison among groups

\begin{tabular}{|c|c|c|}
\hline Characteristic & Hemoglobin (g/dL) & $p$-value \\
\hline Early hospital readmission & & 0.071 \\
\hline Yes & $11.35(8.20-14.60)$ & \\
\hline No & $10.50(7.40-14.90)$ & \\
\hline Gender & & 0.009 \\
\hline Female & $10.40(7.40-14.90)$ & \\
\hline Male & $10.90(8.70-14.60)$ & \\
\hline Diagnosis & & 0.118 \\
\hline Degenerative & $10.35(7.90-14.90)$ & \\
\hline Idiopathic & $10.50(7.40-14.60)$ & \\
\hline Other ${ }^{\text {a) }}$ & $11.10(8.90-13.50)$ & \\
\hline
\end{tabular}

Values are presented as median (min-max). Bold type is considered statistically significant.

alFailed-back, post-traumatic, Scheuermann, neuromuscular, congenital, postinfection.

\section{Results}

This study comprised 225 surgically treated ASD patients with a median age of 62.0 years, predominantly women (80\%). Of the 225 patients, 82,237 , and six had mild, moderate, and severe anemia at the time of discharge,
Table 5. The severity of anemia at discharge in patients with and without early hospital readmission

\begin{tabular}{lrrrrr} 
& \multicolumn{3}{c}{ Anemia } & Total \\
\cline { 2 - 4 } & Severe & Moderate & Mild & \\
Early hospital readmission & & & & \\
Yes & $1(5.9)$ & $5(29.4)$ & $11(64.7)$ & $17(100.0)$ \\
\hline No & $5(2.4)$ & $132(63.5)$ & $71(34.1)$ & $208(100.0)$ \\
\hline Total & $6(2.7)$ & $137(60.9)$ & $82(36.4)$ & $225(100.0)$ \\
\hline
\end{tabular}

Values are presented as number $(\%)$.

Table 6. Linear regression model results for gender categories

\begin{tabular}{lcrr} 
Model & Standardized coefficients & $t$-value & $p$-value \\
Constant & & 37.221 & $<0.001$ \\
Gender (male) & 0.169 & 2.412 & 0.017 \\
\hline
\end{tabular}

Bold type is considered statistically significant.

respectively. Of these, 17 patients (mild [11, 64.7\%]; moderate $[5,29.4 \%]$; severe $[1,5.9 \%])$ were readmitted within 30 days. The mean $\mathrm{Hb}$ values at discharge were higher in readmitted patients $(p=0.071)$. Demographi$\mathrm{cal}$, radiological, and surgical characteristics of the study population, early readmitted patients, mean $\mathrm{Hb}$ values of the patients at discharge, and comparison among groups are detailed in Tables 1-5. In univariate analysis, only gender was found to be a statistically significant variable. Moreover, the linear regression model, including gender, showed that higher levels of $\mathrm{Hb}$ were associated with the male gender $(p=0.017$ ) (Table 6). Furthermore, infection was the leading cause of readmission $(n=12)$, followed by neurological deficit $(n=6)$, severe back pain $(n=3)$, pleural effusion $(n=1)$, hematoma $(n=1)$, radicular pain $(n=1)$, and implant (screw) failure $(\mathrm{n}=1)$. Statistically significant improvements were discovered in HRQoL parameters using ODI, SF-36 PCS, and SRS-22 1 year postsurgery for the entire study population $(p<0.001)$. However, except for SRS-22, HRQoL improvements did not reach statistical significance in early readmitted patients in the first year of postsurgery (Table 7 ).

\section{Discussion}

The results of this study demonstrated that low $\mathrm{Hb}$ values at discharge did not have any impact on EHR rates in surgically treated patients with ASD. Moreover, it also 
Table 7. Descriptive analysis for health-related quality of life parameters in patients with low hemoglobin levels

\begin{tabular}{|c|c|c|c|c|}
\hline \multirow{2}{*}{ HROOL parameters } & \multicolumn{3}{|c|}{ Severity of anemia } & \multirow{2}{*}{ Total } \\
\hline & Severe & Moderate & Mild & \\
\hline COMI baseline & $5.13(0.00-9.80)$ & $6.25(0.00-10.00)$ & $4.63(0.00-10.00)$ & $5.68(0.00-10.00)$ \\
\hline COMl 1st year & $4.10(1.00-4.80)$ & $3.00(0.00-9.20)$ & $3.15(0.00-9.00)$ & $3.15(0.00-9.20)$ \\
\hline ODI baseline & $42.00(10.00-78.00)$ & $42.00(2.00-78.00)$ & $41.00(2.00-78.00)$ & $42.00(2.00-78.00)$ \\
\hline ODI 1st year & $26.00(12.00-72.00)$ & $22.00(2.00-60.00)$ & $32.00(2.00-53.00)$ & $28.00(2.00-72.00)$ \\
\hline SRS-22 baseline & $2.93(2.11-4.00)$ & $2.63(1.42-4.50)$ & $2.77(1.22-4.40)$ & $2.67(1.22-4.50)$ \\
\hline SRS-22 1st year & $3.72(2.63-3.90)$ & $3.50(1.58-4.75)$ & $3.25(1.83-4.50)$ & $3.44(1.58-4.75)$ \\
\hline SF-36 PCS baseline & $31.24(15.43-46.67)$ & $35.29(20.26-63.58)$ & $33.60(19.40-57.09)$ & 35.08 (15.43-63.58) \\
\hline SF-36 PCS 1st year & $38.63(15.42-48.51)$ & $40.23(24.18-58.05)$ & $41.42(22.74-61.86)$ & $40.69(15.42-61.86)$ \\
\hline SF-36 MCS baseline & $57.91(47.66-61.70)$ & $38.35(11.98-64.76)$ & $43.58(14.13-66.84)$ & 40.09 (11.98-66.84) \\
\hline SF-36 MCS 1st year & $58.89(45.37-62.80)$ & 46.38 (12.51-63.54) & $46.81(20.50-64.24)$ & 46.89 (12.51-64.24) \\
\hline
\end{tabular}

Values are presented as median (min-max).

COMI, Core Outcome Measures Index; ODI, Oswestry Disability Index; SRS-22, Scoliosis Research Society-22 questionnaire; SF-36, 36-item Short-Form Health Survey; PCS, physical component summary; MCS, mental component summary.

showed that EHR was associated with poor improvements in QoL parameters within 1 year of postsurgery. The findings of the current research suggested that clinical awareness of the parameters other than anemia may be more important at the time of early readmission.

This study is a rare example evaluating the effect of "anemia at discharge" on QoL and EHR in patients who underwent major spinal surgery. The results are consistent with prior studies investigating the role of anemia in spinal surgery [14-16].

Anemia may be an adaptive response to illness and/ or a marker of illness, and assessing the linkage between $\mathrm{Hb}$ concentration and treatment outcomes is difficult when more time elapses between the anemia duration and the event [17]. Nonetheless, this potentially harmful effect could be associated with increased 30-day hospital readmissions if postoperative anemia resulted in tissue hypoxia. The results of the current study did not show any association between the low $\mathrm{Hb}$ values at discharge, EHR from all causes, and readmissions. However, the sample size was relatively small. Cho et al. [18] and Shehata et al. [19] evaluated the patients undergoing major surgical procedures and found that discharge $\mathrm{Hb}$ concentration was not associated with 30-day readmissions. In contrast, Koch et al. [20], Muzarelli et al. [21], and Rubel et al. [22] demonstrated that postoperative low $\mathrm{Hb}$ levels markedly affect postoperative readmission rates.

Improving exercise tolerance and facilitating functional recovery during the rehabilitation period to have high $\mathrm{Hb}$ levels is recommended [8]. A patient with low $\mathrm{Hb}$ with good iron reserves may recover much faster than those with suboptimal iron reserves [23]. Thus, Halm et al. [2] concluded in a cohort study of 551 patients that transfusion after hip fracture surgery reduced the risk of readmission but did not decrease mortality or improve mobility. Postoperative intravenous iron administration found that its use significantly reduced the percentage of patients receiving a transfusion [24]. In addition, Jans et al. [25] reported that moderate anemia has no or only a negligible effect on early functional recovery after major orthopedic surgery. HRQoL parameters have become increasingly important in the evaluation of surgical outcomes in ASD. Moreover, the present study did not find any correlation between low $\mathrm{Hb}$ levels on discharge and HRQoL parameters in a relatively few patients (Table 8). When early readmitted patients were taken apart, only improvements in SRS-22 reached statistical significance, and the current findings suggested poor improvements in early readmitted patients usinf HRQoL parameters at 1-year follow-up.

This study has several limitations inherent to its retrospective design and the associated possibility of bias. The occurrence and duration of anemia (how long a patient spent at a given $\mathrm{Hb}$ level; iron deficiency) is likely as important as or may be more important than the level of anemia. Any degree of preoperative anemia and the application of blood transfusion may be associated with 


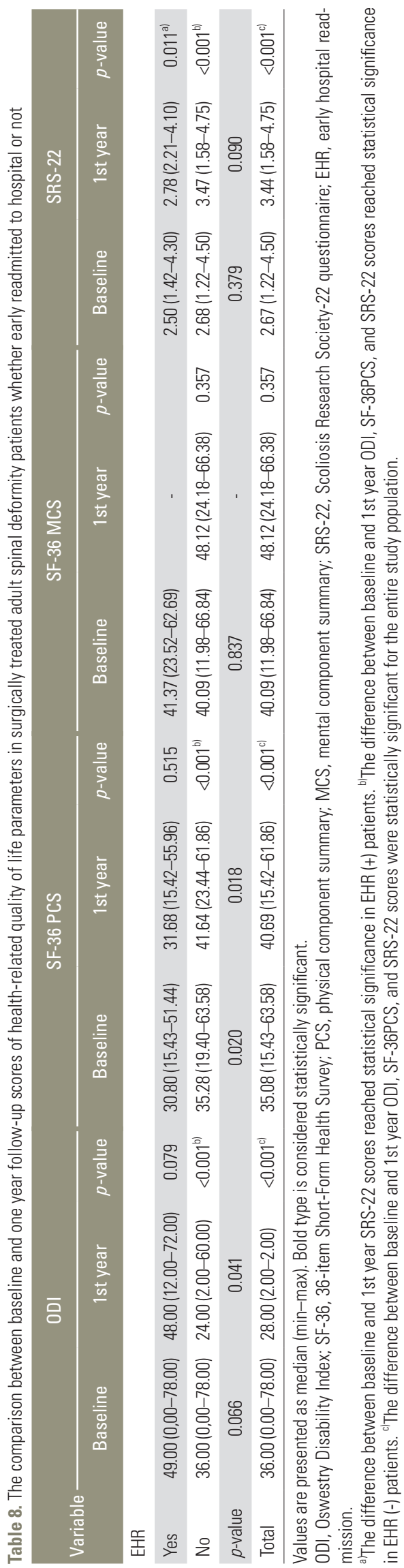

increased length of hospital stay and EHR after controlling for other variables [14,26-28]. Moreover, valuable intraoperative characteristics such as the existence of acute blood loss, intra- or postoperative hypotension, and electrocardiographic changes may influence treatment outcomes $[29,30]$. The Hb level at discharge may only be a transient representation of the anemia severity. Iron studies may be a more reliable indicator of the anemia status. A patient with low $\mathrm{Hb}$ with good iron reserves may recover much faster than those with suboptimal iron reserves [24]. In addition, malnutrition in older patients is a significant predictor of readmission or mortality in both the very early and in the late periods following hospital discharge other than anemia [31,32]. As those parameters were unreachable through a multicenter database at the time of the present research, their effects that may have had beneficial scientific contributions were not evaluated. Furthermore, a small number of patients were discharged with severe anemia. Thus, the results do not necessarily indicate causality because of the possibility that anemia is a surrogate marker of intraoperative events or procedural complexity that eventually resulted in complications. Although 225 patients were included in the entire study sample, patients discharged with $\mathrm{Hb}$ values of $8 \mathrm{~g} / \mathrm{dL}$ represented only $2.7 \%$ of the sample making the study underpowered in this sense (the achieved power of this study is 0.32 [rho=0.10, $\alpha=0.05$ ] while taking 225 patients). The propensity score-matched analyses may have been affected by a relatively small sample size, which further highlights the need for validation of these findings in a larger sample.

\section{Conclusions}

The results of this study demonstrated that the occurrence and the severity of anemia at discharge are not associated with EHR in surgically treated patients with ASD. Although the number of the early readmitted patients was fairly low to perform any further statistical analysis, the findings of the current research suggested that clinical awareness of the parameters other than anemia may be more important at the time of early readmission. Thus, improvements in HRQoL scores were poor in early readmitted patients 1 year postsurgery. These consequences present the merit of future investigations with a more detailed and larger data set. 


\section{Conflict of Interest}

No potential conflict of interest relevant to this article was reported.

\section{Acknowledgments}

European Spine Study Group is a clinical research group funded by a research grant from DePuy-Synthes.

\section{ORCID}

Vugar Nabi: https://orcid.org/0000-0002-2766-5083; Selim Ayhan: https://orcid.org/0000-0003-0153-3012; Selcen Yuksel: https://orcid.org/0000-0002-8994-8660; Prashant Adhikari: https://orcid.org/0000-0003-1948-9611; Alba Vila-Casademunt: https://orcid.org/0000-0002-4441-4083; Ferran Pellise: https://orcid.org/0000-0002-0644-7757; Francisco Sanchez Perez-Grueso: https://orcid.org/0000-0003-0432-2755; Ahmet Alanay: https://orcid.org/0000-0003-2252-6647; Ibrahim Obeid: https://orcid.org/0000-0002-5602-0508; Frank Kleinstueck: https://orcid.org/0000-0003-2057-2201; Emre Acaroglu: https://orcid.org/0000-0002-8163-2944

\section{Author Contributions}

Conception and design: VN, SA, FSPG, EA; conception: FP, AA, IO, FK, European Spine Study Group; data acquisition: VN, AVC, FP, FSPG, AA, IO, FK, EA; analysis of data: SY; drafting of the manuscript: VN, SA, PA, EA; critical revision: VN, SA, EA; and obtaining funding, administrative support, supervision: European Spine Study Group.

\section{References}

1. Shander A, Javidroozi M, Ozawa S, Hare GM. What is really dangerous: anaemia or transfusion? $\mathrm{Br} \mathrm{J} \mathrm{An-}$ aesth 2011;107 Suppl 1:i41-59.

2. Halm EA, Wang JJ, Boockvar K, et al. Effects of blood transfusion on clinical and functional outcomes in patients with hip fracture. Transfusion 2003;43:135865.

3. Pasricha SR, Colman K, Centeno-Tablante E, GarciaCasal MN, Pena-Rosas JP. Revisiting WHO haemoglobin thresholds to define anaemia in clinical medicine and public health. Lancet Haematol 2018;5:e60-2.
4. Eisenstaedt R, Penninx BW, Woodman RC. Anemia in the elderly: current understanding and emerging concepts. Blood Rev 2006;20:213-26.

5. Kulier A, Levin J, Moser R, et al. Impact of preoperative anemia on outcome in patients undergoing coronary artery bypass graft surgery. Circulation 2007;116:471-9.

6. Lin JD, Lenke LG, Shillingford JN, et al. Safety of a high-dose tranexamic acid protocol in complex adult spinal deformity: analysis of 100 consecutive cases. Spine Deform 2018;6:189-94.

7. Everhart JS, Sojka JH, Mayerson JL, Glassman AH, Scharschmidt TJ. Perioperative allogeneic red bloodcell transfusion associated with surgical site infection after total hip and knee arthroplasty. J Bone Joint Surg Am 2018;100:288-94.

8. Lawrence VA, Silverstein JH, Cornell JE, Pederson T, Noveck H, Carson JL. Higher Hb level is associated with better early functional recovery after hip fracture repair. Transfusion 2003;43:1717-22.

9. Conlon NP, Bale EP, Herbison GP, McCarroll M. Postoperative anemia and quality of life after primary hip arthroplasty in patients over 65 years old. Anesth Analg 2008;106:1056-61.

10. Aurouer N, Obeid I, Gille O, Pointillart V, Vital JM. Computerized preoperative planning for correction of sagittal deformity of the spine. Surg Radiol Anat 2009;31:781-92.

11. Obeid I, Bourghli A, Larrieu D, et al. The global tilt: evaluation of a parameter considering the global spinopelvic alignment. J Med Liban 2016;64:146-51.

12. Protopsaltis T, Schwab F, Bronsard N, et al. The T1 pelvic angle, a novel radiographic measure of global sagittal deformity, accounts for both spinal inclination and pelvic tilt and correlates with health-related quality of life. J Bone Joint Surg Am 2014;96:1631-40.

13. Epstein AM, Jha AK, Orav EJ. The relationship between hospital admission rates and rehospitalizations. N Engl J Med 2011;365:2287-95.

14. Khanna R, Harris DA, McDevitt JL, et al. Impact of anemia and transfusion on readmission and length of stay after spinal surgery: a single-center study of 1187 operations. Clin Spine Surg 2017;30:E1338-42.

15. Manoharan SR, Baker DK, Pasara SM, Ponce B, Deinlein D, Theiss SM. Thirty-day readmissions following adult spinal deformity surgery: an analysis of the National Surgical Quality Improvement Program 
(NSQIP) database. Spine J 2016;16:862-6.

16. Akins PT, Harris J, Alvarez JL, et al. Risk factors associated with 30-day readmissions after instrumented spine surgery in 14,939 patients: 30 -day readmissions after instrumented spine surgery. Spine (Phila $\mathrm{Pa}$ 1976) 2015;40:1022-32.

17. Kang T, Park SY, Nam JJ, Lee SH, Park JH, Suh SW. Patient blood management during lumbar spinal fusion surgery. World Neurosurg 2019;130:e566-72.

18. Cho BC, DeMario VM, Grant MC, et al. Discharge hemoglobin level and 30-day readmission rates after coronary artery bypass surgery. Anesth Analg 2019;128:342-8.

19. Shehata N, Forster A, Li L, et al. Does anemia impact hospital readmissions after coronary artery bypass surgery? Transfusion 2013;53:1688-97.

20. Koch CG, Li L, Sun Z, et al. Magnitude of anemia at discharge increases 30-day hospital readmissions. J Patient Saf 2017;13:202-6.

21. Muzzarelli S, Leibundgut G, Maeder MT, et al. Predictors of early readmission or death in elderly patients with heart failure. Am Heart J 2010;160:30814.

22. Rubel NC, Chung AS, Wong M, et al. 90-Day readmission in elective primary lumbar spine surgery in the inpatient setting: a nationwide readmissions database sample analysis. Spine (Phila Pa 1976) 2019;44:E857-64.

23. Perelman I, Winter R, Sikora L, Martel G, Saidenberg E, Fergusson D. The efficacy of postoperative iron therapy in improving clinical and patient-centered outcomes following surgery: a systematic review and meta-analysis. Transfus Med Rev 2018;32:89-101.

24. Steuber TD, Howard ML, Nisly SA. Strategies for the management of postoperative anemia in elective orthopedic surgery. Ann Pharmacother 2016;50:57885.
25. Jans O, Bandholm T, Kurbegovic S, et al. Postoperative anemia and early functional outcomes after fasttrack hip arthroplasty: a prospective cohort study. Transfusion 2016;56:917-25.

26. Elsamadicy AA, Ren $\mathrm{X}$, Kemeny $\mathrm{H}$, et al. Independent associations with 30- and 90-day unplanned readmissions after elective lumbar spine surgery: a national trend analysis of 144123 patients. Neurosurgery 2019;84:758-67.

27. Phan K, Dunn AE, Kim JS, et al. Impact of preoperative anemia on outcomes in adults undergoing elective posterior cervical fusion. Global Spine J 2017;7:787-93.

28. Nunez J, Comin-Colet J, Minana G, et al. Iron deficiency and risk of early readmission following a hospitalization for acute heart failure. Eur J Heart Fail 2016;18:798-802.

29. Hori D, Hogue C, Adachi H, et al. Perioperative optimal blood pressure as determined by ultrasound tagged near infrared spectroscopy and its association with postoperative acute kidney injury in cardiac surgery patients. Interact Cardiovasc Thorac Surg 2016;22:445-51.

30. Hirsch J, DePalma G, Tsai TT, Sands LP, Leung JM. Impact of intraoperative hypotension and blood pressure fluctuations on early postoperative delirium after non-cardiac surgery. Br J Anaesth 2015;115:41826.

31. Stratton RJ, Hebuterne X, Elia M. A systematic review and meta-analysis of the impact of oral nutritional supplements on hospital readmissions. Ageing Res Rev 2013;12:884-97.

32. Sharma Y, Miller M, Kaambwa B, et al. Malnutrition and its association with readmission and death within 7 days and 8-180 days postdischarge in older patients: a prospective observational study. BMJ Open 2017;7:e018443. 